\title{
Perpetuation of Powdery Mildew Infection and Identification of Erysiphe australiana as the Crape Myrtle Pathogen in Mid-Tennessee
}

\author{
Ainong Shi and Margaret T. Mmbaga, Tennessee State University, Otis A. Floyd Nursery Research Center, 472 \\ Cadillac Lane, McMinnville 37110
}

\begin{abstract}
Shi, A., and Mmbaga, M. T. 2006. Perpetuation of powdery mildew infection and identification of Erysiphe australiana as the crape myrtle pathogen in mid-Tennessee. Plant Dis. 90:10981101.

The fungus Erysiphe lagerstroemiae is commonly known as the powdery mildew pathogen in crape myrtle (Lagerstroemiae indica) in the United States, and Erysiphe australiana is the powdery mildew pathogen reported in Japan, China, and Australia. The teleomorph often used to identify powdery mildew fungi rarely develops in crape myrtle, and in our observations, ascocarps never formed. Our study showed that the crape myrtle pathogen overwintered as mycelia on dormant buds. The internal transcribed spacer (ITS) regions of rDNA and the intervening 5.8S rRNA gene were amplified using standard polymerase chain reaction (PCR) protocols and the universal primer pairs ITS1 and ITS4. PCR products were analyzed by electrophoresis in a $1.5 \%$ agarose gel and sequenced, and the ITS PCR product was $666 \mathrm{bp}$ from ITS1/ITS4 and 704 bp from ITS1-F/ITS4. BLAST analysis of the sequence of the PCR products showed identical similarity with E. australiana reported in Japan, China, and Australia. Comparison of ITS sequences with information in the GenBank on other powdery mildew fungi showed a closest alignment (93\% similarity) to Erysiphe juglandis that infects walnut. Specific primers for $E$. australiana were developed and evaluated for use as diagnostic tools. Out of 12 specific primer pairs evaluated, four primer pairs and four double primer pairs were highly specific to E. australiana and did not amplify Erysiphe pulchra of dogwood, Erysiphe syringae of common lilac, Erysiphe circinata of maple, or Phyllactinia guttata of oak. The E. australiana-specific primers amplified 16 samples of crape myrtle powdery mildew collected from diverse locations in midTennessee. These results clearly showed that the crape myrtle powdery mildew in mid-Tennessee was caused by E. australiana. Specific primers reported in this article provide a diagnostic tool and may be used to confirm the identity of crape myrtle powdery mildew pathogen in other areas in the United States and wherever the disease occurs.
\end{abstract}

Additional keywords: Uncinula, Uncinuliella australiana

Powdery mildew is the most important disease of crape myrtle in nursery production systems and in landscape plantings (13). Severe infections occur in spring and early summer in field-grown plants, but greenhouse-grown plants develop severe infections year-round. White cottony mycelia and conidiospores cover leaves, shoots, and inflorescence, causing distortions, leaf curling, and reduced rate of plant growth. Young and succulent tissues are more susceptible than older hardened tissue (13). Infected plants defoliate prematurely, infected parts of the plant usually become distorted, and infected flowers may fail to open; severe infections cause stunting. A primary impact of the disease is aesthetic, but infected plants require a longer period to reach prime size for sale

Corresponding author: Margaret T. Mmbaga

E-mail: Mmmbaga@tnstate.edu

Accepted for publication 23 March 2006.

DOI: 10.1094/PD-90-1098

(C) 2006 The American Phytopathological Society and may have reduced sale price. To control this disease, growers use fungicide applications that start soon after bud break and are repeated two to three times at 10to 14-day intervals (27). This increases production costs and reduces net income from plant sales.

Powdery mildew is the most commonly recognized disease of crape myrtle (Lagerstroemiae indica L.), its hybrids, and a related plant, Lagerstroemiae parviflora in eastern, southern, and western United States $(11,20)$. Heirloom L. indica selections commonly grown in landscapes as well as the compact crape myrtle 'Petite Pink' are highly susceptible to the disease; but some hybrids are resistant (11). Powdery mildew has been the only significant disease of crape myrtle in mid-Tennessee landscape plants and at Tennessee State University germ plasm evaluation plots in McMinnville, TN. While powdery mildew symptoms are easily identified, little is known about the pathogen. Ascocarps rarely form on crape myrtle, and thus it is difficult to identify the pathogen at the time the disease is prevalent (20). The fungus, Erysiphe lagerstroemiae (West), was reported as the causal agent of powdery mildew in crape myrtle in the southern United States (25) and is commonly cited as the crape myrtle powdery mildew pathogen $(11,13,20$; website for the Clemson University home and garden information center). However, Erysiphe (sect Uncinula) australiana (McAlpine) U. Braun has been reported as the causal pathogen in China, Japan, and Australia (2,7,28-31). Although three fungi, E. australiana, E. lagerstroemiae, and Phyllactinia guttata, have been previously reported to infect crape myrtle in the United States (8), only E. lagerstroemiae is commonly known and often cited as the powdery mildew pathogen $(11,13,20,25)$.

Literature searches revealed evidence that powdery mildew of crape myrtle was actively studied and fungicides that are effective in controlling this disease have been recommended, but information on the causal pathogen was scarce $(11,20)$. First report on E. lagerstroemiae as the causal agent of powdery mildew in crape myrtle in the United States was in 1933 (25) before DNA analysis was available to validate the taxonomy of many fungi. Even now, there is no sequence of E. lagerstroemiae in the GenBank, but sequences of internal transcribed spacer (ITS), 18S, and 28S rDNA for Uncinula australiana, currently known as E. australiana (3), are available. The objectives of this study were: (i) to examine disease development and understand the method for winter survival, (ii) to use DNA sequence analysis to identify the powdery mildew pathogen, and (iii) to develop ITS-specific primers for easy diagnosis of the pathogen.

\section{MATERIALS AND METHODS}

Powdery mildew disease development and the crape myrtle pathogen in midTennessee. Powdery mildew prevalence and disease development from natural infection were evaluated in nursery and landscape plantings from April 2003 to August 2005. Plants in most nurseries were kept disease-free by using fungicide applications that started at bud break, but the disease was often severe in locations where pesticides were not used; these included landscape areas and Tennessee State University germ plasm evaluation plots in McMinnville, TN. Samples of infected branches were collected from susceptible crape myrtle accessions including 'Petite Pink' and the heirloom crape 
myrtle commonly found in diverse landscapes in mid-Tennessee. A total of 10 samples were collected monthly in April to June and October to December, and each sample consisted of four to five terminal branches (10 to $15 \mathrm{~cm}$ long). Landscapes sampled were diverse in size and type, including public and privately owned locations, wherever powdery mildew symptoms were prominent, with at least $1.6 \mathrm{~km}$ between sample locations. Disease samples were examined under a dissecting microscope at $\times 35$ and $\times 90$ magnification (Olympus SZX 12) and evaluated for the presence of mycelia and ascocarps on stems, leaves, flowers, and fruits.

In addition, observations were made on six plots of unknown crape myrtle cultivar at the University experimental farm, McMinnville, where 72 plots were planted with a powdery mildew susceptible crape myrtle for a disease management study using a randomized complete block design. Disease development was observed in six nontreated plots, and samples were collected and examined under a dissecting microscope at $\times 35$ and $\times 90$ magnification as described above. Six nurseries in Warren County, TN, were also observed, but were not sampled because fungicide applications had been used to control the disease. Another 16 samples of powdery mildew infected terminal branches were collected from diverse landscapes wherever powdery mildew symptoms were observed in locations that had not been sampled as described above. Each sample consisted of 10 to 15 terminal branches (10 to $20 \mathrm{~cm}$ long). The 16 samples were examined for ascocarps, and the pathogen was identified by using ITS-specific primers developed for E. australiana.

DNA extraction, amplification, and sequence analysis. Powdery mildew mycelia for DNA analysis were carefully isolated from infected leaves by using a scalpel; most samples contained some host tissue mixed in the mycelia. Approximately 2 to $3 \mathrm{mg}$ (fresh weight) of mycelia was used for DNA extraction using DNeasy Plant Mini Kit (Qiagen Inc., Valencia, CA). Each DNA sample was diluted to approximately $25 \mathrm{ng} / \mu \mathrm{l}$ for polymerase chain reaction (PCR). DNA amplification was performed using standard PCR procedures. Each $50-\mu$ reaction mixture contained $1.3 \mu$ template DNA (or no DNA template for a negative control), 1 unit Taq polymerase (Promega, Madison, WI), $4 \mathrm{mM} \mathrm{MgCl} 2,200 \mu \mathrm{M}$ dNTPs, and $0.5 \mu \mathrm{M}$ of each primer (ITS1 and ITS4). A Techne Progene (Princeton, NJ) thermal cycler was used. In general, PCR annealing temperatures were set five degrees lower than the lowest melting temperature for each primer pair and ranged from 58.3 to $64.5^{\circ} \mathrm{C}$. Thermocycling profiles consisted of an initial denaturation $(5 \mathrm{~min})$ at $94^{\circ} \mathrm{C}$ followed by 42 cycles of denaturation $\left(1 \mathrm{~min}\right.$ at $\left.93^{\circ} \mathrm{C}\right)$, annealing $(1 \mathrm{~min} 10 \mathrm{~s}$ at $\left.46^{\circ} \mathrm{C}\right)$, and extension $(1 \mathrm{~min} 40 \mathrm{~s}$ at $\left.72^{\circ} \mathrm{C}\right)$. A final extension cycle $(5 \mathrm{~min}$ at $72^{\circ} \mathrm{C}$ ) was included to allow completion of partial products, and it was followed by a terminal incubation at $4^{\circ} \mathrm{C}$. PCR products were analyzed by electrophoresis in a $1.5 \%$ agarose gel in $0.5 \times$ TBE (TrisBorate-EDTA) buffer. Gels were stained with ethidium bromide $(0.5 \mu \mathrm{g} / \mathrm{ml})$ and DNA was visualized using UV light.

PCR products for ITS region (approximately 704 and $666 \mathrm{bp}$ ) were purified using QIA quick PCR Purification Kit (Qiagen) and sequenced using an ABI 377XL PRISM automatic sequencer (Davis Sequencing Inc., Davis, CA). ITS sequences were edited with BioEdit software (12) and then compared with GenBank information using BLAST search (1).

Development of ITS-specific primers for powdery mildew pathogen of crape myrtle. The ITS region sequence data for E. australiana was used to design ITSspecific primers for the powdery mildew pathogen of crape myrtle. A software, Primer3 (18), was used to develop three forward primers and four reverse primers. A total of 12 primer pairs designed from all pair-wise combinations of primers $(3 \times$ 4) were evaluated on crape myrtle powdery mildew pathogen and its host (L. indica). To test for specificity, the primers were also evaluated on other powdery mildews from the local area, E. syringae from lilac, E. pulchra from dogwood, E. circinata from maple, and P. guttata from oak. In addition, the specific primers were evalu- ated on 16 other samples of crape myrtle powdery mildew collected from different locations in mid-Tennessee.

Evaluation of the specific primers by using multi-primer PCR analysis. In addition to the standard PCR to evaluate the ITS-specific primers, a procedure of multi-primer PCR was used in which two primer pairs were combined to create two polymorphic bands together as a molecular marker. This procedure was expected to increase specificity and reduce false positives by producing two bands to indicate specificity. In this procedure, two primer pairs were used in each PCR reaction, one forward primer and two reverse primers or two forward and one reverse primer. All combinations of specific primer pairs were evaluated as six double primer pairs: (i) ua-f1/ua-r1 + ua-f2/ua-r1, (ii) ua-f1/ua-r2 + ua-f3/ua-r2, (iii) ua-f1/ua-r3 + ua-f3/uar3, (iv) ua-f1/ua-r4 + ua/f3/ua-r4, (v) uaf1/ua-r3 + ua-f1/ua-r4, and (vi) ua-f3/ua-r3 + ua-f3/ua-r4 (Table 1). The double primer pairs were evaluated on powdery mildew pathogens of crape myrtle, dogwood $(E$. pulchra), lilac (E. syringae), E. circinata from maple and $P$. guttata from oak. Standard PCR protocols described above were followed, and volume of each doubleprimer PCR reaction was $100 \mu \mathrm{l}$.

\section{RESULTS}

Powdery mildew disease development and perpetuation of the disease. Powdery mildew symptoms started soon after bud break, and disease severity increased rapidly for a short time in spring when it was

Table 1. Internal transcribed spacer (ITS)-specific primers and all pair-wise combinations designed for powdery mildew pathogen of crape myrtle; the primer names, sequence, annealing temperatures, and polymerase chain reaction (PCR) product sizes corresponding to the ITS region of the Tennessee samples (GenBank accession AY789478) and Erysiphe australiana (GenBank accession AB022408)

\begin{tabular}{llcc}
\hline $\begin{array}{l}\text { Primer } \\
\text { designations }\end{array}$ & $\begin{array}{l}\text { Primer sequence }\left(\mathbf{5}^{\prime} \text { to } \mathbf{3}^{\prime}\right) \\
\text { and pair-wise combinations }\end{array}$ & $\begin{array}{c}\text { Annealing } \\
\text { temperatures }\left({ }^{\circ} \mathbf{C}\right)\end{array}$ & $\begin{array}{c}\text { PCR product size } \\
\text { (bp) }\end{array}$ \\
\hline ua-f1 & cegtgccgactttaatgttt & 58.35 & N/A \\
ua-f2 & tagcccaactcgtgttgtca & 60.4 & N/A \\
ua-f3 & gcccaactcgtgttgtcata & 60.4 & N/A \\
ua-r1 & gcgtagagcctacaccgaga & 64.5 & N/A \\
ua-r2 & cgcgagaaacaaatactacgc & 60.61 & N/A \\
ua-r3 & cgacacaattcttgcttcgt & 58.66 & N/A \\
ua-r4 & ccatcagtgtcgttctgtcg & 62.45 & N/A \\
1 & ua-f1/ua-r1 & 58.35 & 415 \\
2 & ua-f1/ua-r2 & 58.35 & 434 \\
3 & ua-f1/ua-r3 & 58.35 & 488 \\
4 & ua-f1/ua-r4 & 58.35 & 452 \\
5 & ua-f2/ua-r1 & 60.4 & 315 \\
6 & ua-f2/ua-r2 & 60.4 & 334 \\
7 & ua-f2/ua-r3 & 58.66 & 388 \\
8 & ua-f2/ua-r4 & 60.4 & 352 \\
9 & ua-f3/ua-r1 15.4 & 313 \\
10 & ua-f3/ua-r2 & 60.4 & 332 \\
11 & ua-f3/ua-r3 & 60.4 & 386 \\
12 & ua-f3/ua-r4 & 60.4 & 350 \\
& ITS1/ITS4 & 60.4 & 666 \\
& ITS1-F/ITS4 & - & 704 \\
\hline
\end{tabular}

${ }^{a}$ Primers from Qiagen.com were designated as forward primers (ua-f1, ua-f2, and ua-f3) and reverse primers (ua-r1, ua-r2, ua-r3, and ua-r4).

b PCR product size for all pair-wise combinations amplified from crape myrtle powdery mildew Tennessee samples of GenBank accession no AY789478 produced sizes similar to that postulated from Erysiphe australiana in GenBank accessions (AB022408). 
relatively cool. As temperatures increased, disease severity gradually declined in July and August, but it started to increase again in late September to early October until the end of the season. Even when overall symptoms and disease severity had declined, leaves on terminal branches were often distorted and reduced in size, and inflorescence were covered with mycelia. Infected flower buds often failed to open, thus reducing the ornamental value of crape myrtle bloom. Overall, the disease was severe in spring; disease symptoms decreased in midsummer and increased again in autumn; and severe infection was associated with early defoliation.

Throughout this study, ascocarps were not observed. Microscopic observations on samples collected from October to December showed that stems in terminal branches were covered with mycelia that adhered tightly on the stems. The following spring, disease symptoms started on the overwintered mycelia and spread to new tissue. Observations of the overwintered mycelia on stems revealed new hyphal growth spreading onto young leaf petioles and leaf lamina, and where leaf lamina touched the infected stem, infection was evident on points of contact. The new mycelial growth produced an abundance of conidiospores, and infection spread to nearby leaves and to most of the young succulent tissue. It was clear that the mycelia on terminal branches played a significant role in winter survival and perpetuation of the disease from one season to the next.

Infection in autumn was associated with early infection the following spring and suggested that infected dormant buds were the source of primary inoculum and the perpetuation of the crape myrtle powdery mildew pathogen from one season to the

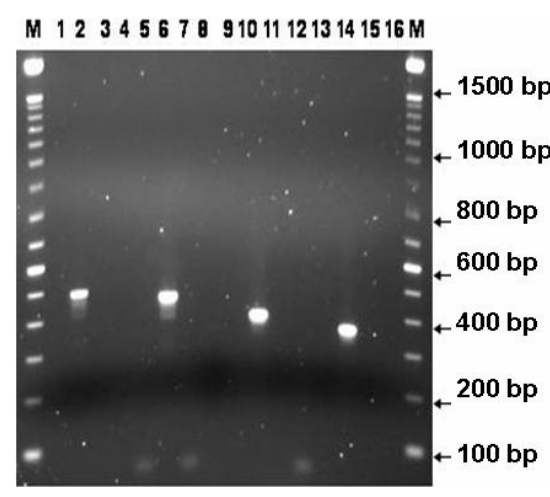

Fig. 1. Polymerase chain reaction amplification of DNA from crape myrtle (Lagerstroemiae indica) host plant (lanes 1, 5, 9, 13) and powdery mildew pathogens from crape myrtle (lanes 2, 6, 10, 14), lilac (Erysiphe syringae lanes 3, 7, 11, 15), and dogwood (E. pulchra lanes 4, 8, 12, 16) by using four internal transcribed spacer (ITS)-specific primers designed for $E$. australiana: (i) ua-f1/ua-r3 (lanes 1 to 4), (ii) ua-f1/uar4 (lanes 5 to 8), (iii) ua-f3/ua-r3 (lanes 9 to 12), and (iv) ua-f3/ua-r4 (lanes 13 to 16). Lane $M$ is a 100-bp molecular weight marker. next. Young branches near the base of the trees were often covered with powdery mildew even when the upper part of the plant did not show disease symptoms. Such infection was observed throughout the season, and it is reasonable to presume that the microenvironment created by the shading of the young branches near the base of trees was highly favorable to powdery mildew infections. Landscape plants that had been cut back before bud break had delayed infection and overall developed less disease than plants that were not cut back.

DNA analysis of the ITS region. The universal primer pair ITS1-F/ITS4 (9) amplified DNA of the crape myrtle powdery mildew pathogen and produced a band of approximately 704 bp (Table 1). The universal primer pair ITS1/ITS4 (26) produced a band of approximately $666 \mathrm{bp}$ (Table 1). BLAST analysis of the sequence of the PCR products from our samples (GenBank accession AY789478) showed identical similarity with Erysiphe australiana (GenBank accession AB022408) reported in Japan, China, and Australia. Comparison of ITS sequences with information in the GenBank on other powdery mildew fungi showed a closest alignment of $93 \%$ similarity to Erysiphe juglandis that infects walnut. All isolates gave similar results and clearly suggested that the pathogen causing powdery mildew in crape myrtle was E. australiana reported in Japan, China, and Australia.

ITS-specific primers developed for crape myrtle powdery mildew pathogen. The band sizes from the 12 ITS-specific primer pairs are presented in Table 1. All 12 primers amplified the crape myrtle powdery mildew pathogen and did not amplify DNA of the host plant. However, two of the primer pairs, ua-f2/ua-r1 and

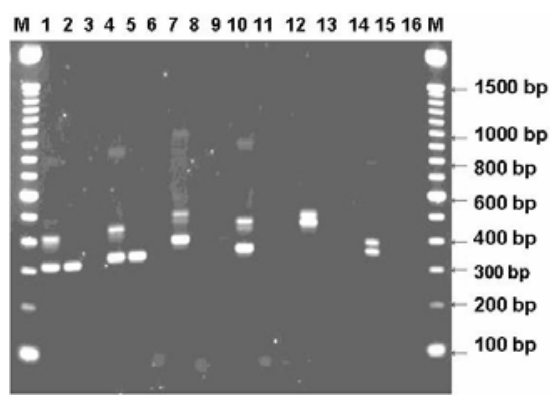

Fig. 2. Polymerase chain reaction amplification of DNA from powdery mildew pathogens of crape myrtle (lanes $1,4,7,10,13,16$ ), lilac (Erysiphe syringae lanes 2, 5, 8, 11, 14, 17), and dogwood (E. pulchra lanes 3, 6, 9, 12, 15, 18) by using six internal transcribed spacer (ITS)specific double primer pairs designed for $E$. australiana: (i) ua-f1/ua-r1 + ua-f2/ua-r1 (lanes 1 to 3 ), (ii) ua-f1/ua-r2 + ua-f3/ua-r2 (lanes 4 to 6), (iii) ua-f1/ua-r3 + ua-f3/ua-r3 (lanes 7 to 9), (iv) ua-f1/ua-r4 + ua-f3/ua-r4 (lanes 10 to 12 ), (v) ua-f1/ua-r3 + ua-f1/ua-r4 (lanes 13 to 15 ), and (vi) ua-f3/ua-f3 + ua-f3/ua-r4 (lanes 16 to 18). Lane $\mathrm{M}$ is a 100-bp molecular weight marker. ua-f3/ua-r2, amplified E. pulchra of dogwood; one primer pair, ua-f1/ua-r1, gave mixed results with $E$. syringae of lilac; and none of the primers amplified E. circinata of maple or $P$. guttata of oak. Nine primer pairs showed specificity to the crape myrtle powdery mildew pathogen; four primer pairs, ua-f1/ua-r3, ua-f1/ua-r4, ua-f3/ua-r3, and ua-f3/ua-r4, were most stable and produced highly specific bands (Fig. 1). When the polymorphic bands amplified from the four primer pairs were purified and sequenced, the sequence was identical to the corresponding locations in the ITS region of E. australiana. The four ITSspecific primer pairs can be used as a diagnostic tool for $E$. australiana in crape myrtle. All 16 samples of crape myrtle powdery mildew collected from different locations in mid-Tennessee produced identical results with ITS-specific primers and were identified as E. australiana. These results confirmed that E. australiana was the pathogen of powdery mildew in crape myrtle in mid-Tennessee.

ITS-specific primers evaluated using multi-primer PCR analysis. The PCR results from the six double primer pairs are presented in Figure 2. Only E. australiana showed double bands, i.e., molecular markers from all six double primer pairs (i) ua-f1/ua-r1 + ua-f2/ua-r1, (ii) ua-f1/uar2 + us-f3/ua-r2, (iii) ua-f1/ua-r3 + uaf3/ua-r3, (iv) ua-f1/ua-r4 + ua/f3/ua-r4, (v) ua-f1/ua-r3 + ua-f1/us-r4, and (vi) uaf3/ua-f3 + ua-f3/ua-r4. Although E. pulchra showed one band with two of the double primer pairs, ua-f1/ua-r1 + uaf2/ua-r1 and ua-f1/ua-r2 + ua-f3/ua-r2, they did not count as markers because they were single bands (Fig. 2). Results from this study clearly indicated that none of the six double primer pairs produced polymorphic markers in E. pulchra and E. syringae. Thus, the six double primers provide an additional tool in the identification of E. australiana of crape myrtle (Fig. 2).

\section{DISCUSSION}

Our observations confirmed previous reports that powdery mildew of crape myrtle overwinters on the dormant buds $(11,20)$. In early spring, the overwintered mycelia spread rapidly to young branches, leaf petioles, leaf lamina, and the whole plant. Thus, disease management would be most effective when control treatments are initiated soon after bud break. Plants that had been cut back before bud break had delayed infection and lower disease severity than plants that were not cut back, and this was attributed to the removal of the source of primary inoculum. These results suggested that cultural disease control methods may include cutting back the young branches that carry most of the overwintered mycelia and primary inoculum. Although the overwintered mycelia was not quantified, perpetuation of the pathogen from one season to the next re- 
sulted in severe infection on the same trees year after year.

Because ascocarps are often not present when disease symptoms are prominent, it is difficult to confirm the identity of the powdery mildew pathogen in crape myrtle. DNA analysis of the ITS region has been widely used to identify and distinguish plant pathogens $(10,14-17,19,21-24)$, and many ITS sequences from fungal pathogens are available in GenBank. In addition, ITS-specific primers have been used as a diagnostic tool for powdery mildew fungi (16). Our results on DNA analysis of the ITS region showed clearly that E. australiana is the powdery mildew pathogen of crape myrtle at Tennessee State University, Nursery Research Center, McMinnville, $\mathrm{TN}$, and in many diverse landscapes at different locations in mid-Tennessee.

Previous reports that E. lagerstroemiae was the pathogen causing powdery mildew in crape myrtle in the United States $(11,13,20,25$; website for the Clemson University home and garden information center) do not mention that E. australiana and $P$. guttata have also been reported to infect crape myrtle in the United States (8). Thus, it was reasonable to assume that $E$. lagerstroemiae was the powdery mildew pathogen at the Tennessee State University germ plasm evaluation plots and other crape myrtle plantings in mid-Tennessee. Technical progress in electron microscopy and molecular biology has strongly influenced changes in the taxonomy of the powdery mildew fungi $(2-4,6,17,21,23,24,28)$. The taxonomy of many pathogenic fungi has been revised based on current information, and some fungi have been renamed $(3,4)$. In 1987, Braun reported that all specimens of $E$. lagerstroemiae were actually the anamorph of Uncinula australiana (2). Based on the ITS region DNA analysis, the dogwood powdery mildew pathogen, Microsphaera pulchra, was also changed to E. pulchra (4), and the genera Uncinueliella, Uncinula, and Microsphaera were placed in one genus, Erysiphe $(3,4)$.

When this study was initiated, it was assumed that $E$. lagerstroemiae was the crape myrtle pathogen, and our search for ascocarps was futile. Our results of sequence analysis of the ITS region showed clearly that E. australiana is the powdery mildew pathogen in crape myrtle in midTennessee, and all 16 powdery mildew isolates from different locations were of $E$. australiana. The ITS-specific primers (Figs. 1 and 2) designed from the E. australiana DNA sequence were highly specific to E. australiana. Studies on crape myrtle powdery mildew may use the ITSspecific primers developed in this study to confirm the identity of the pathogen in their local areas; such studies would help to confirm whether or not E. australiana is widespread within the United States. Our samples showed only one pathogen, and it is assumed that the occurrence of $P$. guttata in mid-Tennessee was not common during the period of this study. The ITSspecific primers reported in this article provide a useful tool in pathogen diagnosis and may be used to confirm the identity of crape myrtle powdery mildew in different areas.

\section{LITERATURE CITED}

1. Altschul, S. F., Madden, T. L., Schaffer, A. A., Zhang, J., Zhang, Z., Miller, W., and Lipman, D. J. 1997. Gapped BLAST and PSI-BLAST: A new generation of protein database search programs. Nucleic Acids Res. 25:3389-3402.

2. Braun, U. 1987. A monograph of the Erysiphales (powdery mildews). Beih Nova Hedwigia 89:1-700

3. Braun, U., Cook, R. T. A., Inman, A. J., and Shin, H. D. 2002. The taxonomy of the powdery mildew fungi. Pages 13-55 in: The Powdery Mildews: A Comprehensive Treatise. American Phytopathological Society, St Paul, MN.

4. Braun, U., and Takamatsu, S. 2000. Phylogeny of Erysiphe, Microsphaera, Uncinula (Erysiphaceae) and Cystotheca, Podosphaera, Sphaerotheca (Cystothaceae) inferred from rDNA ITS sequences-Some taxonomic consequences. Achlechtendalia 4:1-33.

5. Cheng, J., Zhao, L., and Zhou, D. 1983. A Preliminary Study on Uncinuliella australiana (McAlp.) Zheng et Cheng in Kunming. J. Southwest Forestry College 3:23-27

6. Cook, R. T. A., Inman, A. J., and Billings, C. 1997. Identification and classification of powdery mildew anamorphs using light and scanning microscopy and host range data. Mycol. Res. 101:975-1002

7. Cunnington, J. H., Takamatsu, S., Lawrie, A. C., and Pascoe, L. G. 2004. Molecular identification of anamorphic powdery mildews (Erysiphe). Australas. Plant Pathol. 32:421-428.

8. Farr, D. F., Bills, G. F., Chamuris, G. P., and Rossman, A. Y. 1989. Fungi on Plants and Plant Products in the United State. American Phytopathological Society, St Paul, MN.

9. Gardes, M., and Bruns, T. D. 1993. ITS primers with enhanced specificity for basidiomycetes-application to the identification of mycorrhizae and rusts. Mol. Ecol. 2:113-118.

10. Godfrey, S. A., Monds, R. D., Lash, D. T., and Marshall, J. W. 2003. Identification of Pythium oligandrum using species-specific ITS rDNA PCR oligonucleotides. Mycol. Res. 107:790796.

11. Hagan, A. K. 2004. Crape myrtle diseases. Pages 114-116 in: Diseases of Woody Ornamentals and Trees in Nurseries. R. K. Jones and D. M. Benson, eds. American Phytopathological Society, St Paul, MN.

12. Hall, T. A. 1999. BioEdit: A user-friendly biological sequence alignment editor and analysis program for Window 95/98/NT. Nucl. Acids. Symp. Ser. 41:95-98.

13. Jones, R. K. 1982. Powdery mildew. Pages $24-$ 25 in: Diseases of Woody Ornamental Plants and Their Control in Nurseries. R. K. Jones, ed. N. C. Agric. Ext. Serv., Raleigh, NC

14. Kiss, L., Bolay, A., Takamatsu, S., Cook, R. T. A., Limkaisang, S., Ale-Agha, N., Szentivanyi, O., Boal, R., and Jeffries, P. 2002. Spread of the North American snowberry powdery mildew fungus, Erysiphe symphoricarpi (syn. Microsphaers symphoricarpi), to Europe. Mycol. Res. 106:1086-1092.

15. Kiss, L., Cook, R. T. A., Saenz, G. S., Cun- nington, J. H., Pascoe, I., Bardin, M., Nicot, P. C., Takamatsu, S., Sato, Y., and Rossman, A. Y 2001. Identifcation of two powdery mildew fungi, Oidium neolycopsersici $\mathrm{sp}$. Nov. and $O$. lycopersici, infecting tomato in different parts of the world. Mycol. Res. 105:684-697.

16. Mmbaga, M. T., Klopfenstein, N. B., Kim, M. S., and Mmbaga, N. C. 2004. PCR-based identification of Erysiphe pulchra and Phyllactinia guttata from Cornus florida using ITS-specific primers. For. Pathol. 34:321-328.

17. Mori, Y., Sato, Y., and Takamatsu, S. 2000. Evolutionary analysis of powdery mildew fungi using nucleotide sequences of the nuclear ribosomal DNA. Mycologia 92:47-93.

18. Rozen, S., and Skaletsky, H. J. 2000. Primer3 on the WWW for general users and for biologist programmers. S. Krawetz and S. Misener, eds. Bioinformatics Methods and Protocols. MIT, Cambridge, MA.

19. Saenz, G. S., and Taylor, J. W. 1999. Phylogeny of the Erysiphales (powdery mildews) inferred from internal transcribed spacer ribosomal DNA sequences. Can. J. Bot. 77:150 168.

20. Sinclair, W. A., Lyon, H. H., and Johnson, W. T. 1987. Diseases of Tree and Shrubs. Comstock Publishing Associates, a Division of Cornel University Press, Ithca, NY.

21. Takamatsu, S., Hirata, T., and Sato, Y. 1998. Phylogenetic analysis and predicted secondary structures of the rDNA internal transcribed spacers of the powdery mildew fungi (Erysiphaceae). Mycoscience 39:441-453.

22. Takamatsu, S., Hirata, T., and Sato, Y. 2000. Parasitic transition from trees to herbs occurred at least twice in tribe Cytotheceae (Erysiphaceae): Evidence from nuclear ribosomal DNA. Mycol. Res. 104:1295-1303.

23. Takamatsu, S., Hirata, T., Sato, Y., Nomura, Y. and Sato, Y. 1999. Phylogenetic relationships of Microsphaera and Erysiphe (powdery mildews) inferred from the rDNA ITS sequences. Mycoscience 40:259-268.

24. Takamatsu, S., Shin, H. D., Paksiri, U., Limkaisang, S., Taguchi, Y., Thi Binh, N., and Sato, Y. 2002. Two Erysiphe species associated with recent outbreak of soybean powdery mildew: Results of molecular phylogenetic analysis based on nuclear rDNA sequences. Mycoscience 43:333-341.

25. West, E. 1933. Powdery mildew of crape myrtle caused by Erysiphe lagerstroemiae $\mathrm{n}$. sp. Phytopathology 23:814-819.

26. White, T. J., Bruns, T., Lee, S., and Taylor, J. 1990. Amplification and direct sequencing of fungal ribosomal RNA genes for phylogenetics. Pages 315-322 in: PCR Protocols: A Guide to Methods and Applications. M. A. Innis, G. H. Gelfand, J. J. Sninsky, and T. J. White, eds. Academic Press, San Diego, CA.

27. Windham, A. S. 1994. Disease management of woody ornamentals in nurseries and commercial landscapes. Univ. Tenn. Agric. Ext. Serv. PB 1234-25M.

28. Zheng, R. Y., and Chen, G. Q. 1979. Taxonomic studies on the genus Uncinuliella of China. 1. The establishment of the genus $U n$ cinuliella nov. and identification of the Chinese and Japanese species. Acta Microbiol. Sin. 19:280-291.

29. Zhou, D. 1985. A study on powdery mildew of Lagestroemiae indica L. in Kunming: Part one. J. Southwest Forestry College 5:17-25

30. Zhou, D. 1987. A study on powdery mildew of Lagestroemiae indica L. in Kunming: Part two. J. Southwest Forestry College 7:47-54.

31. Zhou, D. 1987. A study on powdery mildew of Lagestroemiae indica L. in Kunming: Part three. J. Southwest Forestry College 7:25-29. 